\section{On the mend}

\author{
Stephen Hancocks OBE \\ Editor-in-Chief
}

Send your comments to the

Editor-in-chief,

British Dental Journal

64 Wimpole Street,

London,

W1G 8YS

Email bdj@bda.org
One of the most satisfactory experiences in life is discovering that an old friend who has been poorly is making a good recovery. It rekindles one's faith in the positive.

In this instance I am pleased to be referring to the FDI World Dental Federation. Three years ago I wrote an editorial expressing my sadness at how the FDI seemed to have lost its way and hoping that good friends and allies might rally to its cause and save it. ${ }^{1}$ I am delighted to report that the recent Annual World Dental Congress, held in Istanbul, was a definite turning point away from the Federation's immediate past history substituting considerable consensus for turmoil and reversing the acrimonious political exchanges of recent meetings. The Turkish Dental Association is to be congratulated on providing the background to the proceedings by organising an excellent Congress. The eventual tally to the scientific, business and exhibition sessions was in excess of 16,000, a figure far higher than those seen at the FDI for many years despite sterling efforts in Hong Kong and Mexico City in the two preceding years.

\section{NEW INITIATIVES}

Helped by the constructive approach of the outgoing president Dr Orlando Monteiro da Silva the Federation launched a new initiative, the Istanbul Declaration, and consolidated some on-going developments on another project, Vision 2020. The Istanbul Declaration, which all those attending were invited to sign, calls for a focus on collaborative practice and upon national, regional and global health leaders 'to recognize oral health as an essential component of global health and promote a reinforced inter-professional collaborative approach in the development of global and national policies'.

The Declaration strongly defends oral health as a fundamental human right and an integrated part of general health and well-being. It further calls upon the 'FDI and its member associations to support a broadened scope of practice for dentists and underline the need for dentists to expand their role and responsibilities for improving the general health and well-being of the community they serve'. This builds on FDI lobbying successes within the WHO which now requires governments of all countries to include oral health in their national health planning by urging collaboration both within the dental profession, and between ourselves and other health professionals. The impetus also takes on the increasing emphasis being placed on the connection between oral health and general health. Consequently, the Declaration aims to strengthen all areas from research through to practice.
Providing the foundation to this initiative is the Federation's work on Vision 2020 which grew out of the FDI General Assembly in Mexico in the autumn of 2011 when it was observed that the dental profession lacked an overarching long-term vision of the main challenges in oral health. The idea was also given strength from the success of the previously FDI-WHO promoted 'WHO goals for the year 2000' which famously advocated a DMFT caries score of no more than 3 at the age of 12 years and which caught imaginations around the world as an achievable target.

Vision 2020 details how the profession can grow in order to make a significant contribution to the improvement of global oral health during the next decade. It defines five areas of priority as cornerstones of a new, responsive and fair model:

- Meet the increasing need and demand for oral healthcare

- Expand the role of existing oral healthcare professionals

- Shape a responsive educational model

- Mitigate the impacts of socio-economic dynamics

- Foster fundamental and translational research and technology. ${ }^{2,3}$

The document is not meant to be operational but to provide avenues which will need to be further explored and discussed: specific strategies, tactical approaches, implementation tools or ready-to-use formulae, which will depend largely on local needs and circumstances. It is seen as the beginning of a continuous process aimed at generating discussion and collaboration between FDI and all its partners.

Many people ask, and have always asked, what the FDI does. It is a difficult question to answer and the best I have ever come up with is to respond that the FDI is what it is; which says everything and nothing about it all at the same time. Certainly the profession would be poorer without it and, arguably optimum oral health for all would be a more distant prospect. The Federation was revitalised and run for many years after WWII from the London practice premises of Dr Gerry Leatherman and then from the third floor of the BDA headquarters where (ironically) my desk is now situated and from which this is written. So perhaps sentiment plays a part as well as realism but either way I am pleased that the FDI is back on the road to health.

Hancocks S. International imperatives. Br Dent J 2010; 209: 365

2. FDI Vision 2020: a blueprint for the profession. Int Dent J 2012; 62: 277.

3. Glick M, Monteiro da Silva O, Seeberger GK et al. FDI Vision 2020: shaping the future of oral health. Int Dent J 2012 62: 278-291. 